\title{
Arsenic Contamination in South Asian Regions: Sources, Challenges and Vision for the Future
}

\author{
T. Awan, S. Batool, S. Naz, H. Munawar, K. Mahboob, S. Saghir and A. Mahmood* \\ National University of Sciences and Technology \\ School of Natural Sciences, H-12, Islamabad, Pakistan \\ *Corresponding Author Email: dr.azhar@sns.nust.edu.pk
}

\begin{abstract}
The contamination of groundwater due to a heavy metal such as arsenic, causes a risk to the availability of clean drinking water around the world. South Asian regions, specifically Bangladesh, India, and Pakistan are reported to be the worst hit of arsenic contamination, with the rural and the distant areas being almost totally relying on arsenic contaminated water. The arsenic contamination of ground water reservoir, is the outcome of various natural and anthropogenic sources, prompting antagonistic impacts on the climate and human well-being. Reliability on such arsenic-loaded water prompts serious health issues such as arsenicosis, skin cancer, cardiac disorders, and respiratory disorders, etc. It has become the necessity of the time to outline the economic and reliable techniques which all the nations whether developed or developing, can successfully adopt for the deduction of arsenic contamination from water. The purpose of this study is to explain the crises caused by naturally occurring arsenic in ground water, challenges faced by humans due to widespread arsenic in South Asian region and modern technologies to mitigate this impact. This article also highlights the importance of the improvements required in the research field for assessments and analysis of drinking water resources, and the development of new methods for the mitigation of chronic toxicity of arsenic.
\end{abstract}

Key words: Arsenic, Arsenicosis, Anthropogenic, Ground water, South Asia.

\section{INTRODUCTION}

The groundwater quality has become a significant problem for individuals living throughout the world because of its rapid contamination. Numerous drinking water assets have been identified with high concentrations of harmful metalloids. Such impurities in water can result in antagonistic health issues as these poisonous metalloids are not biodegradable and can legitimately influence the metabolic frameworks of humans. During the last decades, Arsenic (As), an alleged carcinogen has gained much attention in scientific community and concerned people for its widespread distribution and toxicity in drinking water. The studies show that a huge number of individuals throughout the world consume water highly contaminated with arsenic quantities much higher than the World Health Organization (WHO) suggested breaking point of $10 \mathrm{ppb}$ for each liter of water. Such high levels of As in the environment, aquatic systems, soil, or plant are frightening for the environmental welfare due to daily exposure. Arsenic is an omnipresent component found in the rocks, earth crust, water systems and organisms that mobilizes through both natural and anthropogenic processes. Weathering, microbial digestion and volcanic emissions are a part of the natural phenomenon through which ground water can be polluted by arsenic. Anthropogenic activities like mining, ignition of petroleum derivatives, utilization of arsenical pesticides, herbicides, fertilizers and agricultural chemicals for crops and domesticated animals are the main factors liable for high concentrations of arsenic in soil and surface water. Despite the fact the arsenic introduction through groundwater is a worldwide concern, affecting more than 150 million people, the conditions are intensifying day by day in South Asian regions specifically. Many South Asian countries rely on groundwater for drinking purposes. According to an estimate, more than 100 million people in Southeast Asia are suffering from health and social problems caused by high accumulation of arsenic in environment due to both natural as well as anthropogenic sources. Recent statistics gives the evidence of nearly 800,000 cases of arsenicosis in the region. The amount of arsenic in groundwater has extended to very dangerous high levels (approximately 4,000 ppb), influencing about 250 million individuals globally, including Bangladesh, India, Pakistan, China, Nepal, Afghanistan, Taiwan, the USA, Canada, Brazil, Vietnam, Indonesia, Hungary, and Mexico [1]. Almost 100 million individuals are in hazard of As toxicity from groundwater consumption in the South Asian region alone. Intake of As polluted food (as rice, vegetables and fruits) and drinking contaminated wells and tube wells water are the major sources of As accumulation in the human body. Cancer in Lungs, kidney and bladder as well as skin related problems including pigmentation and thickening are alleged to be caused from ingestion of arsenic through food and water intake. Arsenic, specifically in inorganic forms is observed to be the major cause of cancer and in this matter, adequate evidence were provided by the International Agency for Research on Cancer (IARC). Thus, As tainting is of major distress to keep up the viability of environment as well as ecosystems. In order to overcome this problem, it is extremely vital to examine and analyze the As amounts in all the environmental compartments for its possible contact with humans and related health issues. Although research has made progressions in understanding the occurrence, sources and circulation of arsenic in groundwater on a worldwide scale, improvement is still required on regional levels which needs legitimate information and data. The main purposes of this study are to highlight the possible sources and ways of transport of arsenic in the environment, to enlighten the health and social challenges related to arsenic exposure and known modifiers that present 
Mahmood et al., 2020

inconsistency in biological response, and possible technologies and recommendations as well as awareness for multidisciplinary strategies to minimize the impact of arsenic, specifically in south Asian region [2].

\section{GROUNDWATER CONTAMINATION OF ARSENIC IN SOUTH ASIA}

Although arsenic contamination is a worldwide problem, the South Asian region is the most dramatically affected area where a noteworthy number of inhabitants is predicted to be at the risk of arsenic destruction. The arsenic contamination in South Asia has been alluded as "the biggest mass harming in human history" by World Health Organization according to a report published in 2009. Almost 100 million people utilizing As polluted water are living in South Asian countries as a major proportion of people living in this region relies on aquifers for drinking and irrigation purposes. Generally, the irrigation waters are drawn deeper by the installation of tube-wells which cause As contamination. Rapid urbanization, over population and augmentation of intensive irrigation systems are also worsening the problem. The immense health calamities are the consequences of arsenic cycles beginning from the disintegration of arsenic-loaded minerals and rocks in the Himalaya, movement of rocks embedded with arsenic-iron oxides down the Red river systems Brahmaputra-Ganges, and Mekong, Irrawaddy and deposition as deltaic dregs. The erosion of such arsenic adsorbed iron-oxide minerals releases arsenic to the water tables where its amounts can surpass 1000ppb, 100 times the World Health Organization drinking water standard level. The same water is later, made to be utilized by the communities, present in the low-lying deltas of Asia, for drinking and irrigation purposes. Specifically, the rural population of the Bengal basin relies mostly on water obtained from tube wells and wells of which they drink 5-10 L per person each day. According, to a research conducted in 1998-99, 46 $\%$ of the tube wells bear As concentrations above than the World Health Organizational drinking water guideline of $10 \mathrm{ppb}$ $(0.01 \mathrm{ppm})$ signifying that various people residing in this area are broadly unprotected due to toxic As. Adding to this, South Asia is also considered as the most dynamic agronomic part of the world, and mostly depends on As-loaded water for irrigation activities. When such contaminated water from tube wells is used in the irrigation, As may become incorporated in the soils. When such soils are continuously flooded with monsoonal rains, it may result in the contamination of rice fields. The microbial activities in paddy fields also give rise to some volatile methylated As species. Another source of generation of As and its derivatives in South Asian atmosphere is cattle and livestock. The movement of cattle over crop fields and their ingestion of As-contaminated foods and paddy water results in accumulation of As in the meat and is also released as volatile and unstable organometallic As species along with the release of methane, which are produced by cattle through the process of assimilation.

The major countries of South Asia affected by arsenic contamination are mentioned below:

\subsection{Bangladesh}

Bangladesh is one of the most highly influenced country of the world with arsenic pollution facing a critical public health risk as more than 85 million Bengalis consume drinking water polluted with arsenic. 60 of the 64 districts in the country are found to have arsenic levels higher than both the World Health Organization (WHO) limited value (10 ppb) and that of country's standard level of $70 \mathrm{ppb}$ [3]. More than 50,000 hand tube well water samples were collected and examined from nearly 60 districts of Bangladesh, and it was observed that As concentration came out to be $10 \mathrm{ppb}$, and $30 \%$ had As concentration exceeding $50 \mathrm{ppb}$. Besides the intake of As contaminated water, the people of Bangladesh do the irrigation the crops with water. Rice and vegetables crops are of $80 \%$ of the total irrigated regions and need the highest amount of water. A study has shown that the application of arsenic-rich water has led to reduced plant yield, declined plant growth and poor development of the roots systems. The highly impacted crop is rice which is a staple food of people of Bangladesh. Much of the poisoning of the rice crops in Bangladesh is a consequence of accumulation of inorganic As which is considerably more hazardous than organic species of As. A report has concluded that $15 \%$ of the total arsenic consumption is through drinking water, however, nearly $60 \%$ of it is from cooked rice, indicating clearly that rice is the major factor leading to daily arsenic ingestion. This condition has become a critical threat for humans, crops as well as livestock health in Bangladesh. About 300 tube-wells in a village of Bangladesh were surveyed by National Institute of Preventive and Social Medicine and the School of Environmental Studies, concluded that 30\%of the assessed water samples had arsenic levels greater than $50 \mathrm{ppb}$. In another survey, the Rapid Action Program tested 200 villages and concluded that 2000 of nearly 500,000 people were spotted to have arsenic-induced skin lesions. Similarly, a more comprehensive analysis of some rural and distant parts of the country with arsenic-polluted tube-wells and wells was organized, and 1500 adults were tested. Of these, more than 400 were suffering from skin lesions.

\subsection{India}

Several states of India are also reported to be subjected to arsenic toxicity. It was first reported in the surface water of some parts of West Bengal during 1980s [4]. Currently, more than 7 million people of India are found to intake water having As amounts more than $50 \mathrm{ppb}[5]$. In a study of 140,000 tube wells and wells organized in West Bengal showed that about 50\% of these samples had As above than $10 \mathrm{ppb}$ and nearly $25 \%$ had it more than $50 \mathrm{ppb}$. In a research,19 districts and 3,500 villages from 90 blocks were examined carefully and result demonstrated that nine were polluted with As concentrations higher than $50 \mathrm{ppb}$. The source of As in India is related to the various geothermal activities. Arsenic is found in the deposited 


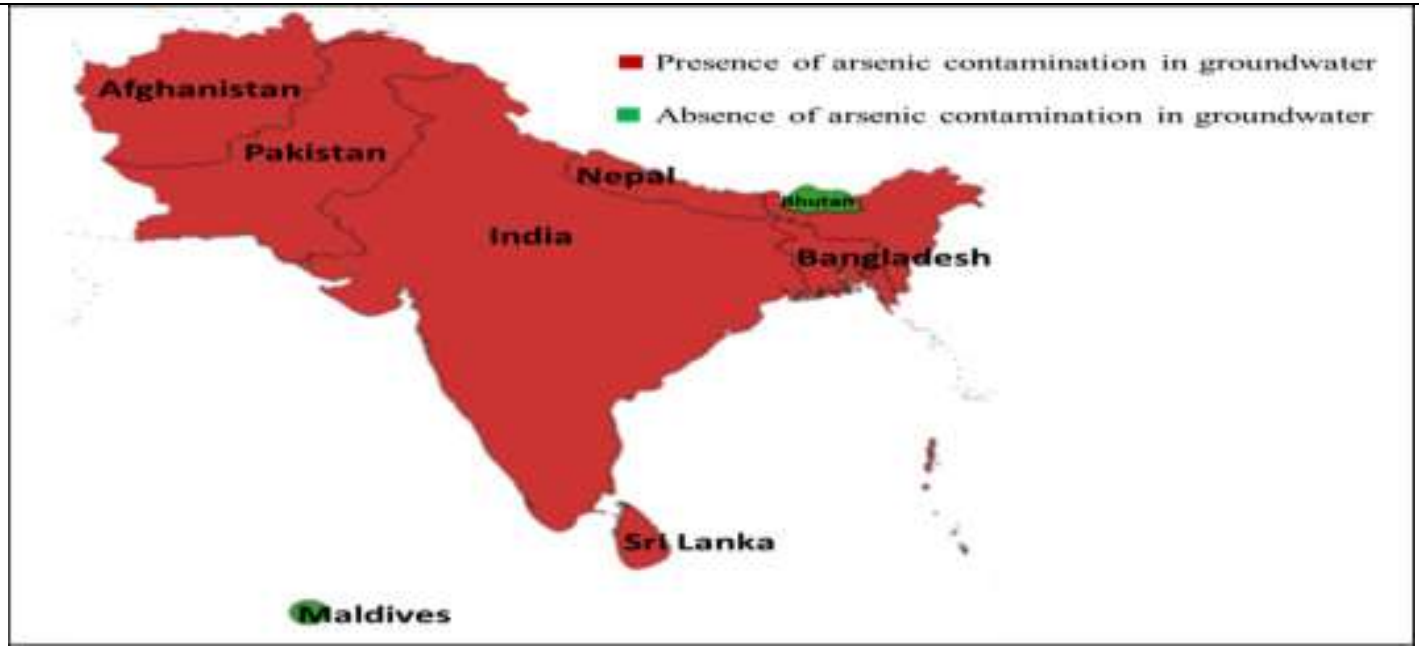

Figure 1. presence and absence of Arsenic in south Asia

dregs of the Gangetic Delta. The process and sources of As discharge and transport in surface water is found to be associated with the number of processes such as the oxidation process of pyrite [6], reduction of Fe-oxyhydroxides[7], reduction of carbon and its compounds and reduction caused by bacteria [8]. Bihar was the first state of India where arsenic poisoning was observed and examined in 2002 [9] ,showing that about $40 \%$ of 1000 samples tested had As amounts greater than 10 ppb and that $23 \%$ had As amounts more than $50 \mathrm{ppb}$. Of 4,513 persons tested, $525(5.5 \%)$ were detected to have various types of As-related skin manifestations [4]. The state of Uttar Pradesh is also subjected to severe As contamination, about 3,901 hand tube wells water samples were checked in the state in a study. Of these, $47 \%$ had As above than $10 \mathrm{ppb}$ and $30 \%$ contained As above than $50 \mathrm{ppb}$. These researches and studies also showed that $15.5 \%$ of 989 people examined were suffering from arsenical skin lesions [4]. In Jharkhand state of India, water samples obtained from 1,024 tube wells and wells from 17 villages of Jharkhand state resulted that nearly $30 \%$ had levels of As more than 10 ppb and $19.4 \%$ had As more than $50 \mathrm{ppb}$. Out of 300 persons selected for medical checkup,80 individuals showed signs of arsenical skin lesions. In Assam, the highest levels of As contents were found beyond the WHO standards were present in a numerous groundwater sample. The sediments in the northern areas of the country also have sand and organic matters, which accumulate and discharge As in groundwater aquifers.

guideline of $0.050 \mathrm{ppm}[11]$.

\subsection{Pakistan}

As of 2007, 364 samples from Gujranwala, Gujrat, Lahore, Narowal, Jhelum, Okara, Sheikhupura, Hafizabad, Mandi Bahauddin, Chakwal, Multan, Kasur and Sialkot were obtained mainly from wells, tube wells, irrigation areas, processing and manufacturing units and a comprehensive analysis was made. Nearly, $90 \%$ of these samples had As concentration below than $10 \mathrm{ppm}$, and 2 percent exceeded $50 \mathrm{ppm}$. The surveys were also done in the Muzaffargarh district of Pakistan where it was analysed that $60 \%$ of the samples were detected with As level over $10 \mathrm{ppb}$, based on 50 groundwater samples analyses [10]. In Pakistan, a maximum number of shallow water tables and tube wells are found to be polluted with arsenic with its amounts much greater than the suggested arsenic level of $10 \mathrm{ppb}$. The agricultural areas of Sindh have the highest arsenic content with its concentration of $46.2 \mathrm{ppb}$ followed by $35 \mathrm{ppb}$ in soil collected from a variety of agricultural areas found in Punjab. The Manchar lake has arsenic levels in range of 11.3-55.8 ppb. A study organized by Pakistan Environmental Protection Agency (PEPA) confirmed that arsenic content in the city of Lahore was in the range of $230-2230 \mathrm{ng} / \mathrm{m}^{3}$.This situation is alarming as this level is considerably higher than many other parts of the world as $100-500 \mathrm{ng} / \mathrm{m}^{3}$ in Calcutta city of India 30ng/ $\mathrm{m}^{3}$ in Wuhan City, China, from 1 to $50 \mathrm{ng} / \mathrm{m}^{3}$ in Los Angeles, USA.

\subsection{Afghanistan}

Ghazni, Wardak and Maidan are the provinces of Afghanistan suffering from severe contamination due to arsenic. Human activities, over-population, industrialization and extensive irrigation have altered the cycling processes of heavy metals as a result of which As accumulation in environment has become a major concern for the people of Afghanistan. Different districts of these areas were studied in detail, paying more attention to the drinking water points and it was reported that the levels of arsenic in these areas were in the range of $0.00-0.99 \mathrm{ppm}$ and $40 \%$ of these sample crossed the WHO guideline values of As with concentrations of $0.01 \mathrm{ppm}$. Moreover, $62 \%$ of examined water trials exceeded the National drinking water quality standard of $0.05 \mathrm{ppm}$ of As. The studies showed that most of the rural and distant population of Afghanistan was the major victim of As contamination.

\subsection{Nepal}


As in several other countries of South Asia, arsenic (As) concentrations in the groundwater of the lowlands of Nepal has reached the levels that are hazardous to humans, animals and plants using the groundwater. The Terai region of southern Nepal is subjected to As contamination where about 50 percent of Nepal's entire population is present. In this region, 90 percent of the people, use groundwater for drinking purposes. UNICEF has estimated that arsenic contamination could affect more than 1.4 million people across 20 districts in Terai. Of the 15000 samples tested to determine the quality of water, $23 \%$ is greater than the WHO drinking-water standards of 0.010 ppm, while $5 \%$ has As more than Nepal's As

\section{SOURCES OF ARSENIC}

The sources of As in the environment are categorized as natural and anthropogenic.

\subsection{Natural sources}

As is the $20^{\text {th }}$ most plentiful component present in earth crust having just a single isotope that occurs in nature with atomic mass 75 and is excessively found in soils, sediments, and water environments. It is the 14th most abundant element present in the water bodies and 12th within humans [12]. South Asian countries as India, Bangladesh, Vietnam, Nepal, Sirilanka, Afghanistan and Pakistan are the worst hit due to As contamination as a major proportion of people living in these countries relies on groundwater. The major natural sources include geologic processes (e.g., sedimentary deposits/rocks, volcanic rocks and soils), weathering, forest fires, soil erosion and volcanic eruptions. Geothermal water also causes accumulation of organic and inorganic species arsenic in groundwater. Most of the natural reservoirs, such as oceans, rocks, crops, forests, atmosphere, biota, and soils. have arsenic in excessive amounts. Although the amounts of arsenic in the surface of the Earth keep fluctuating, the average levels are normally stated to have a range between 1.5 to $5 \mathrm{ppb}$. It is also an important constituent of many minerals in magmatic, hydrothermal, and alluvial rocks and over 200 minerals also contain arsenic in different forms. The natural processes as desorption, oxidation and dissolution of natural arsenic loaded minerals and alluvial deposits cause its extraordinary quantity in groundwater in deltas and alluvial plains although its concentration in the solid phase is not very high. Metals as copper, silver, gold and lead have extensive amounts of arsenic in the form of sulfide ores. Arsenic pyrites (e.g., FeAsS), realgar (AsS), lollingite $\left(\mathrm{FeAs}_{2}, \mathrm{Fe}_{2} \mathrm{As}_{3}, \mathrm{Fe}_{2} \mathrm{As}_{5}\right)$, and orpiment $\left(\mathrm{As}_{2} \mathrm{~S}_{3}\right)$ are the species of arsenic found in several minerals. The aquatic systems contain four main species of As including inorganic forms such as arsenite $(\mathrm{H} 2 \mathrm{AsO} 3-)$, arsenate $(\mathrm{H} 2 \mathrm{AsO} 4-)$, and organic forms (methyl arsenic acid $\left[\mathrm{CH}_{3} \mathrm{AsO}(\mathrm{OH})_{2}\right]$ and dimethyl arsenic acid $\left[\left(\mathrm{CH}_{3}\right)_{2} \mathrm{AsO}(\mathrm{OH})\right]$. Arsenite is 60 times more lethal than arsenate and it is observed that mobility and deposition of arsenic-rich substances from hilly areas to other areas downstream result in deposition of As. Arsenic is emitted directly from rocks by a number of processes under oxygenated and reducing conditions, as a consequence of which much greater quantities of arsenic is created [13]. Later, this arsenic leads to the contamination of other environmental components. In 1976, different villages in Punjab, Haryana, and Himachal Pradesh, Chandigarh and Jharkhand were comprehensively analyzed by the assessment of water obtained from dug wells, wells hand pumps, and spring-water. Through this research, the arsenic levels as high as 545 ppb were found. Almost $90 \%$ of tube wells and wells in Bangladesh are polluted with arsenic. Similarly, many districts of Pakistan are analyzed and the main factors responsible for water contamination with As are mainly associated with the natural processes.

\subsection{Anthropogenic sources}

Anthropogenic sources resulting from human activities have become the most important causes of Arsenic contamination. Main anthropogenic activities responsible for arsenic accumulation in the environment and its various compartments are mining, leachate of gold, lead and copper, metal smelting, waste and plastic incineration processes, fossil fuels and coal combustion, irrigation, the utilization of pesticides (arsenic trioxide, lead ortho arsenate, acid lead arsenate ( $\mathrm{PbHAsO} 4)$, and lead arsenate), herbicides, weed killers, and fungicides; crop desiccants, food preservatives, and food additives for livestock. Studies have shown that extensive removal of contaminated underground water for irrigation purposes has given rise to in increased levels of the metal in surface soils of South Asian regions [14]. Arsenic is used in industrial processes as a green pigment, alloying specie, in the process of glass manufacturing, textiles, paper, metal epoxy resins, food additives, bullets and missiles processing and in the hide burning activities. Arsenic is also emitted from several other industrial and manufacturing units including ash and waste disposal sites, wood and limber industries, during the manufacturing processes of iron and steel. These all are generally point sources of arsenic however, dumping of treated wood causes dramatic removal of arsenic and its leaching into aquatic bodies. The combustion of coil and fossil fuels remove tremendous amounts of arsenic in the form of soluble and volatile oxides which are easily scattered in the atmosphere through wet or dry deposition. When coal and fossil fuels are burnt, volatilization of $\mathrm{As}_{4} \mathrm{O}_{6}$ occurs leading to the discharge of arsenic in the environment which after undergoing the process of condensation eventually returns into the water bodies. The gases released from thermal and nuclear power plants also emit arsenic as the fossil fuel used by such plants is mainly oil and gas which contain As in high amounts. Mine drainage leads to the precipitation of a variety of iron and aluminum substances which play a significant part in the discharge of toxic elements and heavy metals including arsenic. In nature, gold and arsenic-loaded substances coexist in the rocks, and minerals, there is consistently a danger of release of arsenic during gold mining activities. These toxic elements are also color pigments readily used in the cosmetic industry in the manufacturing of eye- 
shadows [15]. It is also found out to be present in the preparatory solutions of electronic cigarettes and the smoke they release. Based on the available toxicology data, the recommended level of metal impurities for these cosmetic products should be less than $5 \mathrm{ppm}$ of. An average estimated level of arsenic used to pressure treat lumber and timber in the form of copper chrome arsenate (CCA) is $70 \%, 22 \%$ in farming compounds, and the remaining is utilized in glass processing, pigments, pharmaceuticals and non-ferrous alloys. Massive contamination of soil, surface and ground water is due to the negligent manufacturing and usage of CCA products, and the improper storage of CCA-treated wood. Another leading factor of arsenic contamination is the cotton ginning, which substantially adds arsenic into the environment.

\section{DISTRIBUTION}

The extensive spreading and circulation of arsenic (As) all over the surface of the earth, soil, plants, minerals, sediments, water bodies, atmosphere, and living organisms results in its dangerous antagonistic adverse impacts on the environment. Hydrosphere and lithosphere contain huge amounts of As in the form of inorganic arsenate with +5 oxidation state $\left[\mathrm{HAsO}_{4}\right]$ and arsenite with +3 oxidation state $\left[\mathrm{H} 2 \mathrm{AsO}_{3}\right]$. Among the above-mentioned forms, Arsenate, the principal form present in aerobic and oxidizing conditions and is thermally more stable in toxic waters. The plants then absorb this species by means of phosphate transporters ( Asher and Reay, 1979 ). However, Arsenite, is predominantly present in anaerobic conditions and reduced environments and is absorbed through nodulin 26 like intrinsic aquaporin. The important factors affecting the transport of these species are temperature, $\mathrm{pH}$ levels, the oxidation-reduction potential, and the existence of oxides and hydroxides of Fe (III), Al (III), Mn (III/IV), moisture and soil minerals. Research have demonstrated the impacts of PH levels on the movement of arsenic species suggesting that the activity of arsenic (As) is also dependent on alkaline desorption processes. It was also found that the highest amounts of arsenic were found in water systems having PH range of 8.1-8.9. Numerous other factors as geographical position of an area including its chemical, geological as well as biological characteristics determine the concentration, transport, effect and fate of As and its derivatives in the environment. The emittance of arsenic (As) to the several environmental sections is mainly dependent on four natural geological phenomena that comprise of basic desorption process, oxidation of sulfide ores, reductive dissolution process, and variety of other geological activities. In all these processes, reductive dissolution is the highly responsible process through which arsenic is released in huge amounts into the atmosphere. The process of reductive dissolution of iron oxides having adsorbed As occurs readily under reducing conditions and is the leading factor causing As contamination in groundwater sources of the regions of South East Asia such as Bangladesh, India, Nepal, Pakistan, China, and Vietnam. Microbes such as bacteria are also involved in the arsenic distribution as they decompose deposits, rocks and ores and separate arsenic (As) accumulated on the surface of iron oxy hydroxides present in these ores and minerals, in this way it gets entered the environment. The extraction of groundwater in high amounts (for irrigation and drinking purposes) from wells and tube wells allows oxygen to enter aquifers, where it undergoes oxidation abiotically, and thus dissolves As-bearing sulfidic minerals. Along with the release of Arsenic, this process is also responsible for the formation of Fe (III), which precipitates readily as Fe (oxy hydrogen) oxides in alkaline medium. The main consequence of this reaction is that Fe (oxy hydrogen) oxide minerals has a high affinity for As so co-precipitation occurs where the volatile As is precipitated out along with iron precipitates. This is considered as the leading pathway responsible for As mobility in the environment [16].

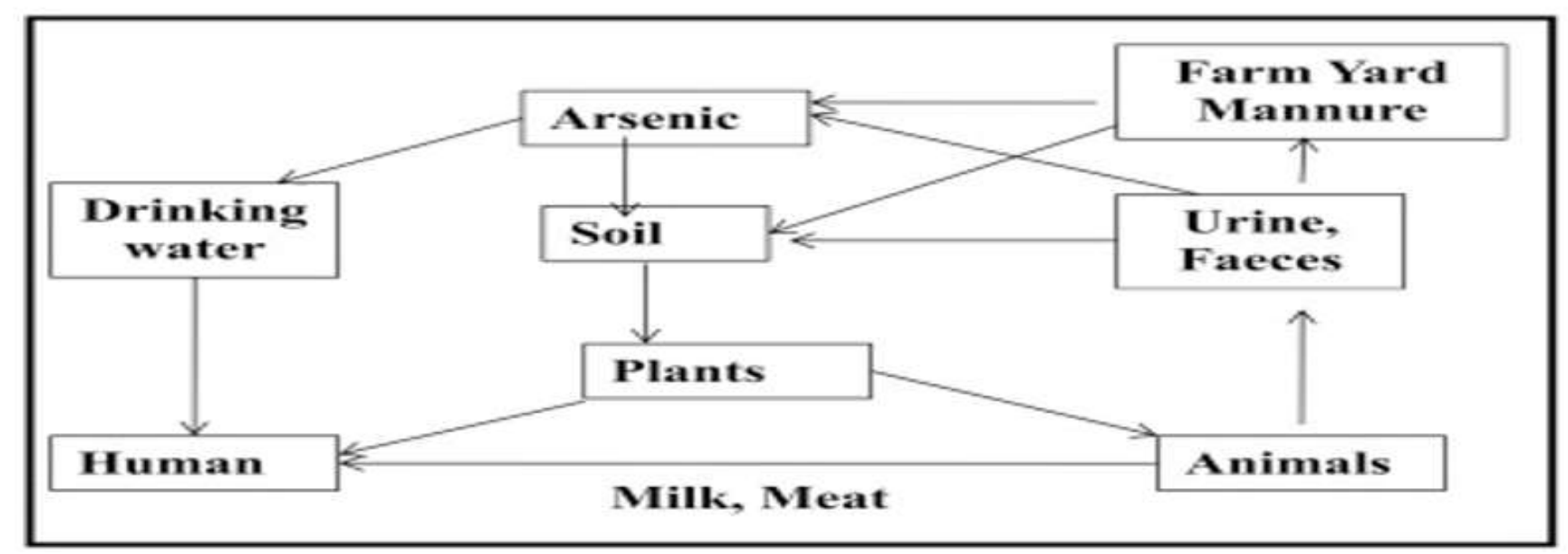

Figure 1 Schematic diagram of arsenic contamination in both human being and livestock [17]

\section{CHALLENGES FACED BY SOUTH ASIA DUE TO ARSENIC CONTAMINATION}

Arsenic has no essential role in human body. In contrast, it causes serious health issues to humans if body is continuously exposed to this toxic metalloid. Inorganic arsenic is confirmed to be the major cause of water contamination at global level. 
Pakistan, India and Bangladesh are among the most effected countries in South Asia. Arsenic may exist in organic or inorganic form. But adverse effects of inorganic arsenic (tracked in water) are more severe as compared to the organic ones (found in seafood). Arsenic is recognized as having carcinogenic effect on human's lungs and skin causing severe skin diseases, neurological diseases, cardiovascular disorders, and reproductive complications.

\subsection{Health risk due to arsenic consumption}

The exposure of arsenic to humans can take place through various ways such as ingestion, inhalation, and skin adsorption. But mostly human exposure to arsenic is through ingestion. High uptake of arsenic has acute toxic effects such as gastrointestinal symptoms such as loss of appetite, vomiting, diarrhoea etc. result in disruption of circulatory and mental functions. For example muscle and joints pain, heart problems, high blood pressure or even death.

\subsection{Effect of Arsenic on humans}

Experiments have shown that arsenic causes serious neurological effects in humans not in animals if its amount is $0.05-0.1$ $\mathrm{mg} / \mathrm{kg} / \mathrm{day}$. Monkeys, dogs and rats were given an exposure of arsenic or arsenate up to $0.72-2.8 \mathrm{mg} / \mathrm{kg} / \mathrm{day}$ (which is a huge amount), but they remained safe [17]. So, such experiments provided strong evidence that inhalation or oral exposure of arsenic is carcinogenic for humans but not for animals. Hence, the dose dependent data experimentally calculated from animals can't be applied for humans as it's not reliable [18].

\subsubsection{Effects on respiratory system:}

Through reports it has been found that both tube well water arsenic and other occupational resources has affected the respiratory system of humans. People working in mining and milling or ores and in smelting industry are mostly exposed to dust and fumes of arsenic which produces irritations in mucous membranes causing a number of diseases like bronchitis, tracheobronchitis, laryngitis, rhinitis 15 resulting in stuffy nose, chronic cough and throat soreness. If arsenic trioxide is inhaled, it may be fatal causing tracheobronchial mucosal and sub mucosal haemorrhage, alveolar haemorrhage and pulmonary oedema. Ground water arsenic toxicity causes chronic asthma and asthmatic bronchitis [18].

\subsubsection{Effects on Cardiovascular system (circulatory system):}

Intake of arsenic-laced drinking water leads to several cardiovascular diseases by affecting the related hormonal processes. Blood vessels and heart are seriously injured due to arsenic exposure. The risk of myocardial and arterial issues is high in children. Reports have analysed those children having an average of $0.6 \mathrm{ppm}$ are subjected to heart related diseases. If low level intake of arsenic (As) is faced, vascular system damage is caused. Example in an endemic disease in Taiwan that is Blackfoot disease. In Taiwan, most of the drinking water contains $0.17-0.8 \mathrm{ppm}$ of arsenic [19].

\subsubsection{Effects on Neurological system:}

Studies and experiments have shown and proven the adverse effects of inorganic arsenic on the nervous system of humans. Just like cardiovascular system, arsenic damages both central and peripheral parts of nervous system [18]. There is a chance of encephalopathy in case of acute exposure of arsenic ( 1 ppb per day) with symptoms including lethargy, headache, coma, hallucinations [20]. If individual is repeatedly exposed to arsenic, contraction in sensorimotor polyneuropathy occurs which has resemblance with Landry-Guillain-Barre Syndrome. After 1 to 5 weeks of exposure, neuropathy appears by axonal degeneration. The main symptoms of encephalopathy are restlessness, increase in urinary urgency, increase in little amount of ethyl alcohol, distractibility, recent memory loss and continuous headache [21]. By neuropsychological testing, it has been seen that panic attacks, somatic symptoms, anxiety, depression. Similarly, continuous exposure to organic and inorganic arsenic causes nerves disorders including misfunctioning of both sensory and motor neurons which causes muscle weakness and reflexes loss [22].

\subsubsection{Carcinogenic effect of Arsenic:}

Chronic exposure to inorganic arsenic causes a long-term disease that is cancer. Some epidemiological studies were made in Taiwan, Canada and Argentina which showed that drinking water containing arsenic has relation with black foot disease, Bowen's disease and skin cancer [23].

Respiratory cancer has caused a number of deaths among the working staff in gold mines, workers using pesticides and workers who are part of smelting process of copper [24]. It is observed that arsenic compounds exposure is majorly causing lung cancer rather than non-arsenic compounds. Lung cancer cases are also reported in workers spraying insecticides that contains inorganic arsenic. The physician, Fishbein has stated that chances of death due to lung cancer increases by 5 to 10 times if the cause of that cancer is inorganic arsenic [25]. IARC (International Agency for Research on Cancer) has also claimed through evidence that inorganic arsenic is the major carcinogen for humans causing skin and lung cancer [26].

Skin cancers are mostly found to be at a single centre but multicentric cases are also found [27]. As skin cancer is associated to be caused from inorganic species of arsenic, many neuroplastic changes of skin that may include Bowen's disease and basal cell carcinoma are found on the trunk region of human's body with arsenic origin [28], [18]. Carcinoma of multiple basal cells is observed to be related with therapy of arsenic [29]. It has been found that this exposure usually occurs via oral pathway, either through medication or contaminated drinking water. Multiple basal cell carcinoma is the most common cancer type among various skin cancers. 


\subsubsection{Effect on Renal System:}

Kidney, being major source of excretions, has high possibility of accumulation of arsenic on repeated exposure. It has been seen that kidney converts arsenic from pentavalent form into trivalent form that is insoluble and toxic form of arsenic. Capillaries, glomerulus, and tubules are the major sites effected by arsenic [30], [31]. These damaged sites cause proteinuria and casts in the urine. Oliguria is the common disease observed but renal failure also may occur if arsenic poisoning is severe. The major solution is dialysis in this case [32].

\subsubsection{Dermatological Effects:}

People consuming water with arsenic level of $0.1 \mathrm{ppb}$ per day were documented as having several skin disorders. Some general effects included infections on palms and soles, hyperkeratosis, hypopigmentation in areas of over pigmentation on face, back and neck [33], [34]. According to some epidemiological studies, 20 to 200 people showed no effects of exposure of Arsenic doses of $0.003-0.01 \mathrm{ppb}$ per day on skin [35].

\subsubsection{Mutagenic Effects of Arsenic:}

Mutations in DNA and genetic alterations are due to secondary mutagens including arsenic. These mutations may range from less severe form; for example, DNA base pair swap, to a more severe form; for example, number clastogenesis (addition, deletion and replacement of parts of chromosome). Some of these problems usually run throughout generations [18]. The idea that arsenic stimulates the genetic destructions by inhibition of DNA repair explains the relation between arsenic exposure amount and rate of chromosomal aberration [36]. Effect of trivalent arsenic is more genotoxic for chromosomal aberrations as compared to pentavalent form of arsenic [37], [18].

\subsubsection{Effect on Enzymatic system of body:}

When the arsenic compounds enter the human body, it gets deposited and absorbed in elementary canal and on various cells of body. This has effect on the enzymatic activity of those cells and lead to the death of such cells [38].

5.2.8.1 Step \# 01_An enzyme breaks the pyruvic acid from glucose in the mitochondria as this pyruvate is going to form pyruvate oxidase complex for oxidative decarboxylation to produce acetyl coenzyme A and $\mathrm{CO}_{2}$. Further these products enter the tricarboxylic acid cycle. In that enzyme, lipoic acid is present comprising of two thiol groups (-SH). Arsenite (trivalent arsenic) prevents the reoxidation of dihydro-lipoid group which is essential for above process to continue by replacing the hydrogens in Thiols forming complex of dihydrolipoyl-arsenite chelate. In the consequence, pyruvate amount in blood increases causing damage to the cell [38].

\subsubsection{Step \# 2}

Inorganic arsenic in the form of arsenate usually causes the blockage of enzymatic processing differently in mitochondria. To continue some enzymatic activity, ADP is converted into ATP by combining with inorganic phosphate. Arsenic hinders this step forming arsenate ester bond by oxidation. As ATP is not formed so source of energy in cells is reduced. Therefore, high energy bonds of Adenosine Triphosphate are not able to be undergo any transformation due to interference of arsenate and this mechanism is referred as arsenolysis [39].

\subsection{Biochemical effects of arsenic}

Inhibition of various enzymes is caused by arsenical compounds in both animals and humans. In rat soleus muscles and 3T3-L1 adipocytes, PAO (Phenyl Arsine Oxide) causes the blockage of glucose transport by inhibiting the insulin activation [40]. Similarly, Arsenite accumulates in liver where it causes inhibition of Pyruvate or $\alpha$-ketoglutarate's NAD- linked oxidation. This is because vicinal thiols; being necessary for the substrate oxidation, forms complex with trivalent arsenic [41].

\subsection{Effect of arsenic on society}

Not only this toxin has health effects but also causing serious social problems. People living in rural areas usually believe in superstitions and often misinterpret the person effected with arsenic as the source of transmittance of that disease being contagious. So, they keep a safe distance from effected people. For the same reason, villagers exclude that person from the society. In Bangladesh and Bengal, poisoning of arsenic creates problems in family relations. Girls are most effected in such cases as the community forbids those girls to marry and married women gets the divorce. In order to avoid such social distancing, effected people do not share their disease with anyone even with doctor. Similarly, children also face discrimination in schools in case they are affected [42].

\subsection{Arsenic Effects on agriculture}

Arsenic contamination in irrigation water is the leading factor behind the degradation of land leading to food chain contamination and loss of yield. Arsenic may accumulate in soil due to long-term use of arsenic-contaminated water. This arsenic absorbed by crops leads to the intake of infected dietary items by humans again leading to health issues. In the longterm, the yield of those crops also decreases. Arsenic affected areas having contaminated water are mainly present in the south and south-west, including Chittagong, Dhaka, and Khulna. Many indications have been shown that arsenic contamination is continuously increasing due to irrigation of arsenic water especially in regions of Bangladesh [43]. Arsenic 
is present in rice crops at a varying concentration in different countries. According to the studies, the type and nature of soil decide the nutritional status of rice grain [44]. Due to the presence of a germ layer in brown rice retaining the inorganic arsenic, it has $80 \%$ more arsenic than in white rice [45].

\subsection{Toxicity of arsenic}

Toxicity of a pollutant is defined as the amount in milligrams of that pollutant present in one kilogram of the body weight which can cause the death of the individuals if they ingest its single dose within few days. The concentration is known lethal dose, commonly referred as LD50. The toxicity of the arsenic is mainly related to the form in which arsenic is present. Comparatively, Inorganic arsenic forms are observed to be much more toxic as compared to the organic ones especially the species of inorganic arsenic with +3 oxidation state are extremely hazardous. Inorganic arsenic compounds are mostly found in drinking water and organic ones in the sea food [46].

Table 1 -Toxicity of arsenic (As) [42]

\begin{tabular}{ll}
\hline Form of arsenic & Oral L/D50 (mg/kg BW) \\
\hline $\mathrm{Ca}_{3}\left(\mathrm{AsO}_{4}\right)_{2}$ & 20 to 800 \\
$\mathrm{As}_{2} \mathrm{O}_{3}$ & 34 \\
$\mathrm{C}_{5} \mathrm{H}_{11} \mathrm{AsO}_{2}$ & $>10,000$ \\
$\mathrm{NaAsO}_{2}$ & 15 to 40 \\
\hline
\end{tabular}

The exposure to acute toxicity of arsenic is not very common however, the low concentration of arsenic is health hazardous. Not only has it caused skin cancer, but long-term exposure to arsenic also causes cancer to the lungs and the bladder. It is also known that arsenic in drinking water is cancer causing to humans. Now what makes arsenic this much toxic to humans is that it does not have either taste or color, so one can be exposed to it without knowing it. Now ingestion of large amount of arsenic leads to many hazardous symptoms of digestive tract leading to death.

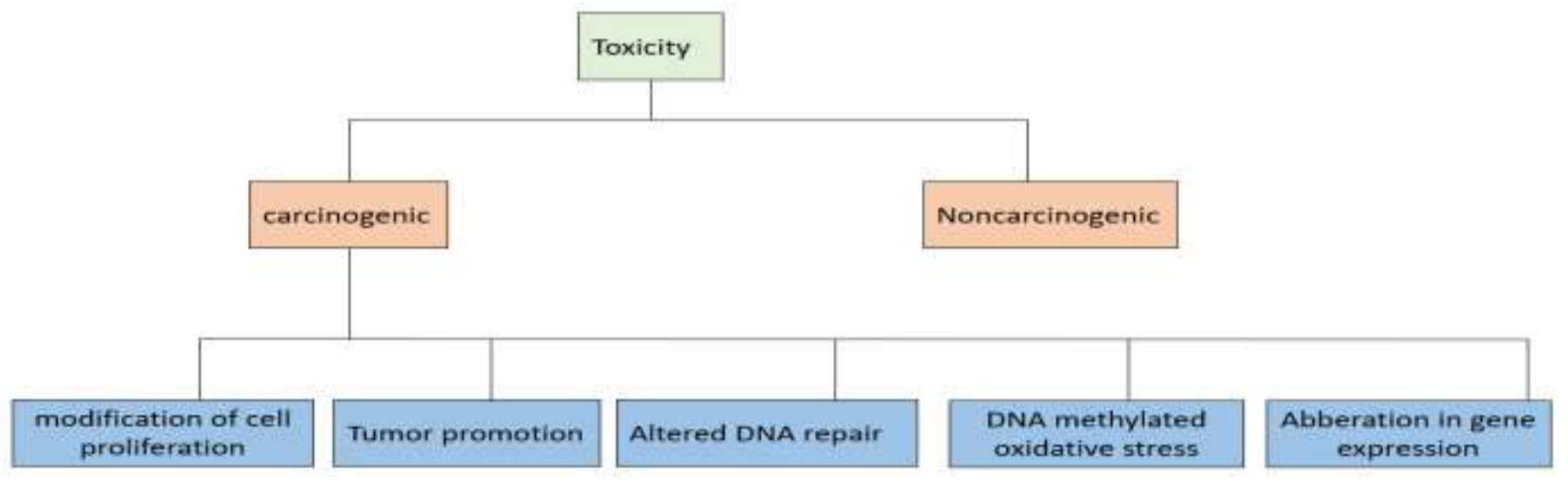

Figure 2 Flowchart describing the various modes of arsenic toxicity. [38]

\section{TECHNOLOGIES USED IN TREATMENT OF ARSENIC CONTAMINATED WATER}

Many of the remedial and corrective technologies have been developed for the treatment of arsenic responsible for contamination of drinking water. Most of these technologies are applied under both laboratory and field processes. The physical and chemical process are applied to arsenic (AS) polluted water. These technologies include:

- $\quad$ Precipitation process

- $\quad$ Adsorption processes

- Ion exchange processes most used method is anion exchange.

- $\quad$ Membrane filtration process

- $\quad$ Greensand filtration

- Biological arsenic removal

- In situ arsenic removal

- Biological oxidation

The technologies such as coagulation, anion exchange, membrane filtration processes are used at the domestic level and are the most used treatment technologies which removes the significant amount of arsenic from the contaminated drinking 
water. Highly developed technologies such as bio-oxidation has also been used to clean the arsenic (As) polluted water but some of these technologies are still at the trial stage.

\subsection{Precipitation}

Precipitation process is followed by the coagulation and filtration are employed to successfully eliminate the arsenic (As) from polluted water. In process adsorptive co-precipitation, we commonly used the hydrolyzing metal such as $\mathrm{Al}^{+3}$ or $\mathrm{Fe}^{+3}$ to treat the contaminated water. The formation of precipitate after coagulation have been removed by the sedimentation process or by performing micro filtration. Coagulation processes involving salts of aluminum, iron and lime are used to treat the arsenic contaminated water to make the water according to the standards of interim primary drinking. In most of the cases the As (V) can easily be treated as compared to As (III) so for this purpose oxidizing agents such as Atmospheric oxygen, hypochlorite and permanganate are used commonly for oxidation of As (III) to As (V). This method is also quite effective to treat other water contaminants such as heavy metal. Precipitation/co-precipitation is successfully capable method to treat the arsenic contaminated water and required highly skilled operator but it is cost effective so generally done at large scale [47].

\subsection{Adsorption}

In adsorption process we use the adsorptive media such as activated alumina or activated carbon onto which surface particles of hydrated Fe (111) oxide are adhered which absorb arsenic from contaminated water. This process may require PH adjustment and spent media regeneration, but it is not a necessity. The capability of adsorption process in removal of specifically arsenic is more than precipitation process as this process can remove other contaminants along with arsenic. Generally, the relatively smaller capacity systems used the adsorption process technology which is cost effective and require less operator expertise [47].

\subsection{Ion exchange}

Ion exchange process generally used by small scale system commonly applied at the domestic level. Ion exchange process is the sludge free operation and easy to handle. The limitation of this process is that it does not remove the As (III) because it not a charged species and present in the form of $\mathrm{H}_{3} \mathrm{AsO}_{3}$ water with the $\mathrm{PH}$ value of 9.0 so in order to remove the As (III) it should be oxidize to $\mathrm{As}(\mathrm{V})$. The $\mathrm{As}(\mathrm{V})$ is a negatively charged specie occur in the form of $\mathrm{H}_{2} \mathrm{AsO}_{4}{ }^{-}$and $\mathrm{HAsO}_{4}^{--}$, so it is easily removed by ion exchange [47].

\subsection{Membrane filtration}

Membrane filtration process is the effective technique for the eradication of As (III) and As(V). We remove the arsenic by applying adsorption, filtration, or electric repulsion. In microfiltration and ultrafiltration process the removal of arsenic highly depends upon the size distribution of arsenic bearing particles. Nano -filtration and reverse osmosis technology can remove the 80 to $90 \%$ of dissolved arsenic present in ground water. Membrane filtration technique is highly sensitive technique to a variety of contaminated water and produce large volume of residual water. But this technique is more expensive as compared to other arsenic treatment technologies so it is not used widely to treat the arsenic contaminated water [47].

\subsection{Biological oxidation}

In this process microorganisms such as Geospirillum arsenophilus, Bacillus and Geospirillum barnesi are used to treat the arsenic (As) polluted water. Microorganism for example bacteria, algae and fungi can play an essential role important role in the oxidation and reduction of As in geochemical cycle. These species of bacteria in their respiratory process uses As (V) as a terminal acceptor. The oxidation of As (III) is done with the help of chemical reagents such as chlorination, potassium permanganate or iron oxide. The use of chemical reagents is highly discouraged because it results in the formation of by products such as trihalomethanes (THMs) and may cause various health problems such as aesthetic problems. This technology effectively removes the arsenic content from the water and under optimum conditions oxidize the As (III) which successfully remove the arsenic contaminant up to $95 \%$ from groundwater. Therefore, biological oxidation technology is cost effective and ecofriendly [47][48].

\subsection{Bucket treatment unit}

In bucket treatment unit we used the process such as coagulation, filtration, adsorption and co precipitation to use this treatment unit at domestic level. Bucket treatment unit consist of two buckets which are placed one above the other with a capacity of $2 \mathrm{~L}$. In one of the bucket chemicals are mixed manually with the help of stirring with the contaminated water and then this water is made to be settled for $1-2$ hours approximately. Then this water carefully moved to the second bucket without causing disturbance in the settled sludge of the first bucket. Therefore, the second bucket encloses the practically treated water.

\subsection{Arsenic Removal Systems}

There are two types of arsenic removal systems which are: 


\subsection{Centralized treatment system}

This system is employed to a city level and provide clean drinking water in cities and bunch of communities attach to the distribution system [47].
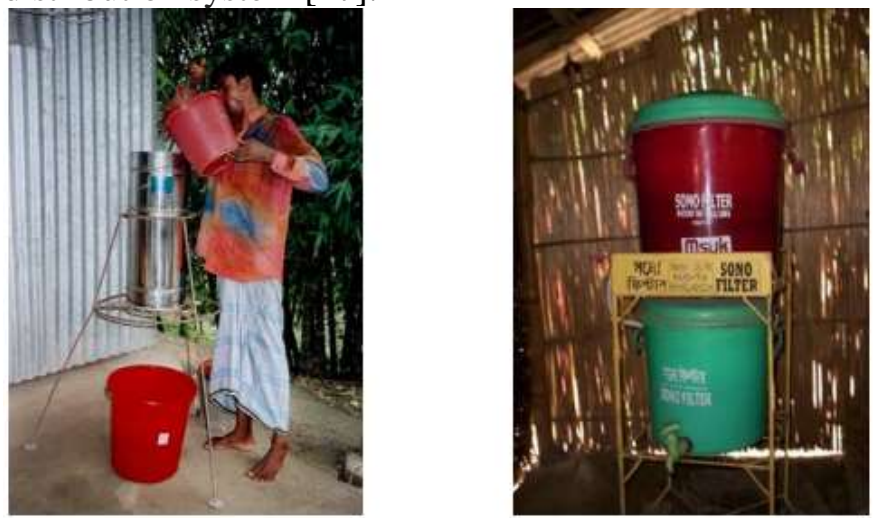

Figure 4 An Alcan filter in Azimpur village Bangladesh (left) and Sono arsenic removal filter (right)

\subsection{Household point-of-use system}

These systems are applied at domestic level on site resources to provide clean drinking water to the several houses closed to that facility [47]. This system is employed to rural areas where centralized systems are unavailable. These systems are applied to tube wells which are feasible short-term solution and comparatively easy to handle. People are familiarizing to use this system. Several POU arsenic removal technologies based on filtration, coagulation and adsorption. Several systems include oxidation system (chlorination, addition of potassium permanganate) which improve the removal efficiency of As (III). The Bangladesh government agreed to four technologies to sell commercially. These technologies are Alcan, Sidko, READ-F and Sono. About 100,000 household use arsenic removal systems in Bangladesh and results are mixed [47].

\subsubsection{Centralized treatment system:}

The treatment systems are employed to remove the arsenic from the contaminated water in both developed and developing countries. These treatment units use many traditional methods such as coagulation, adsorption, and filtration. The membrane filtration process is expensive and result in large volume of residual water, so its use is limited in the treatment process. However, the membrane filtration treatment is highly cost effective when there is blackish ground water, and it contains high content of arsenic along with other impurities and this water is not treated through conventional and adsorptive processes. While treating the arsenic contaminated water it must take into account that the color and taste of water do not change otherwise it will affect the public demand [47].

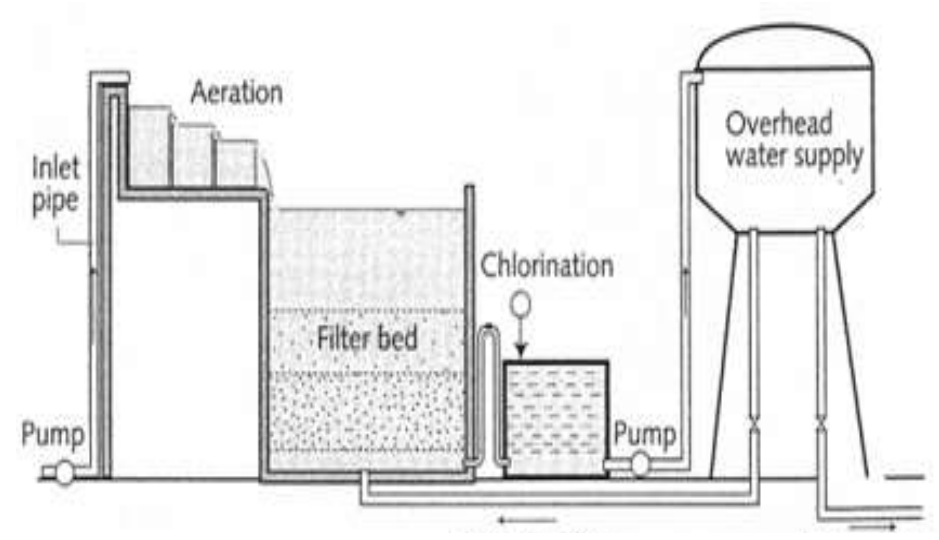

Figure 5 Conventional iron removal treatment unit [47]

Another arsenic removal system is coagulation-separation, in which there is addition of coagulant such as aluminum and iron base salts followed by flocculation and floc separation units such as sedimentation and rapid sand filtration. Appropriate coagulant type, $\mathrm{PH}$ and dosage has been established by simple jar tests because it may affect the arsenic removal effectiveness. It must consider that the efficacy of arsenic removal does not depend only upon the PH and type of coagulant it also depends upon the competence of separation process. This process become easy without sedimentation and flocculation units when relatively low dosage of coagulant is efficient for arsenic removal. In direct filtration the filter media is of critical importance we generally use coarse deep bed or dual media for filtration [47]. When ground water contaminated 
with arsenic is followed by aeration step which typically leads to add the coagulant in arsenic polluted water. We add the oxygen in the aeration step to the polluted ground water which is essential to remove the impurities from ground water such as methane which can cause serious problem during filtration. If the water contains high concentration of iron, addition of oxygen in the aeration process oxidizes the iron and form ferric hydroxide flocs which are comparable with the size of the floc of the coagulant so that coagulant dosage is reduced. Traditional methods to remove iron (Fe) from ground water depends upon the aeration and filtration process to remove the iron $(\mathrm{Fe})$ along with As contaminants while the effectiveness of this process depends upon the variety of ground water and procedure circumstances [47-49].

\section{A Mixing C Sedimentation \\ B Flocculation D Filtration (Upflow)}

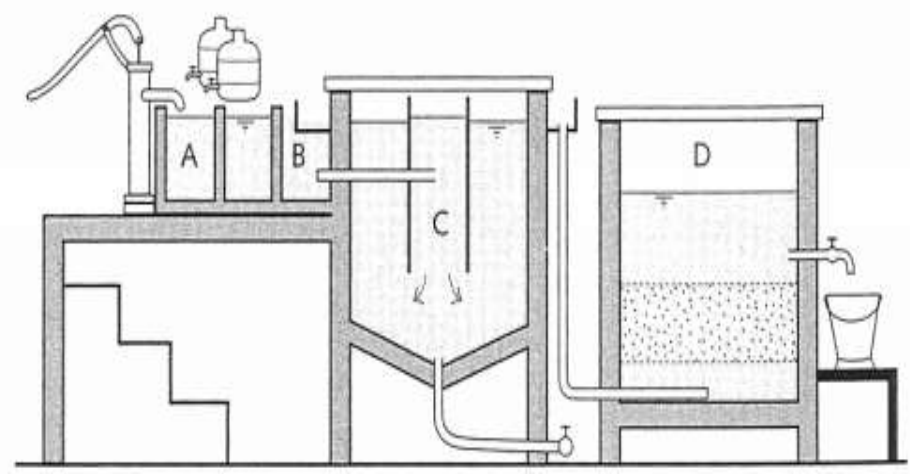

Figure 6 Conventional coagulation-based treatment unit attached to tube well [48]

It is reported in Bangladesh that the use of rapid-sand filtration removes the significant amount of arsenic where the $65 \%$ of ground water comprises iron (Fe) surplus of $2 \mathrm{mg} / \mathrm{l}$. When significant amount of arsenic As (III) is present there is a need of chemical pre-oxidation such as chlorination and ozonation which increases the treatment cost and the need for skilled personnel. Due to chemical oxidation, there is the possibility of development of side products by oxidation and these harms needed to be considered. The restriction of this process is that there is formation of large volume of waste toxic water. While applying this process the option for treatment, waste disposal and cost of this process should be carefully taken into account as a source of arsenic (As) polluted water [47, 50].

\section{AWARENESS}

There lies a risk that communities are not safe when they drink arsenic polluted water. It is highly reinvigorated that remedial strategies must be adopted to lessen the effects of arsenic (As) polluted water. A campaigner Dr. M.I.Zuberi from Rajshahi University of Bangladesh, said that "There should be thorough mitigation action through community involvement. This is important to restore hope to those who are affected and save the community from rapid degradation of society" [47, 50]. Community consciousness movements are required to familiarize the side effects of arsenic (As) polluted water supplies. The mass media can play an important role to publicize the problems and solution of arsenic contamination rather than the alarm. Providing information to the public about the signs and symptoms of arsenic (As) harmfulness as well as the health issues related to it should be considered. Public awareness plans should be carried out paying specific attention to villagers and rural population where generally literacy rate is low. Further, awareness campaigns about arsenic (As) impurity of tube well water and its harmful impacts on humans should be held. Areas accumulated with high concentrations of arsenic (As) in groundwater or soil must be subjected to comprehensive screening of all rice and vegetables fields and the main objective should be to focus on the methods to abate As contamination in agricultural systems. The availability of arsenic (As) in various crop fields as of rice and vegetables should be monitored and examined regularly. Meetings and conferences should be held for the awareness, in some of the areas it should be planned separately or combined so that both women and men are contributed to the meetings. Participants should be encouraged to understand the causes, effect, sources, distribution, and challenges faced due to arsenic contamination and the preventive measures should be explained to minimize the effect. Regular assessments and testing of water obtained from wells and tube wells are also important to overcome the risks associated with arsenic (As) contamination. Once public is convinced about the risk of drinking polluted water next step is to formulate the strategies explaining them the ways to drink clean and save water.

\section{Conclusion}

This article has summarized the occurrences and impacts of arsenic contamination in groundwater around the world specifically in South Asian countries. Comprehensive review of the problems caused by arsenic contamination on human 
Mahmood et al., 2020

health, society and in agricultural fields has also been made in this study. Inadequate education, poverty, lack of awareness, less availability of resources and ineffective health care system are major factors leading to immense plight to severely arsenic affected people. The absence of active monitoring systems makes it difficult to determine that how many people are joining the list of arsenic victims daily. To remediate the crisis caused by As, the early identification of the affected sources should be made possible and then to deliver arsenic pure water to the affected communities. The available alternative of water sources should be considered to tackle the problems caused by arsenic contamination. the modern technologies, conventional and hybrid methods for arsenic removal from the contaminated groundwater should be adopted. The technologies are explained well along with merits and demerits in the article., such as dug well, arsenic-safe deep tube well, rainwater harvesting, and treated surface water. Advanced and innovative surface and ground water management systems that can considerably reduce the geological disturbance of the aquifers, effective treatment of the arsenic (As) victims and adaptation of large-scale purification techniques appear to be the solution of this problem. Depending upon the geological and geomorphological factors as well as considering the socioeconomic and literacy conditions of people of an area, the arsenic-mitigation strategy should be formulated considering all these factors. Whatever be the approach, the people should be have an awareness of the risks and dangers of arsenic contamination and its effects, and their whole-hearted participation is also needed to control the situation. The technical assistance should be provided with chemical plants or biological species to treat the sewerage and sludge storage treatment units. We truly hope that the readers will find this article of considerable interest as article has comprehensively highlighted the origin, distribution, and occurrence of arsenic in ground water, challenges faced by arsenic contamination and the adoption of technologies to mitigate its effect at city and household level.

\section{CONFLICTS OF INTEREST}

The authors declare no conflict of interest.

\section{ACKNOWLEDGMENT}

We would like to thank our honourable Professor Dr-Azhar Mehmood, Associate Professor, National University of Science and Technology, School of Natural Sciences, for

providing necessary guidelines to carry out this study. His continuous support and motivation helped us to achieve our goal readily and effectively.

\section{REFERENCES}

1. Akai, J., Izumi, K., Fukuhara, H., \& Masuda, H. (2004). Applied Geochemistry, 215-230.

2. Akter, K. F., Owens, G., Davey, D. E., \& Naidu, R. (2005). Reviews of environmental contamination and toxicology, $97-$ 149.

3. Akter, K. F., Owens, G., Dawey, D. E., \& Naidu, R. (2005). Rev Environ Contam Toxicol, 97-149.

4. Amitava Mukherjee, M. Amir Hossain, Bhaskar Das, Bishwajit Nayak, Dilip Lodh, Mohammad Mahmudur Abdulrehman, .Mrinal Kumar Sengupta. (2006). J HEALTH POPUL NUTR, 142-163.

5. Andrew A Meharg, M. M. (2003). Environ Sci Technol, 29-34.

6. Rahman, M. M., Naidu, R., \& Bhattacharya, P. (2009). Environmental geochemistry and health, 31(1), 9-21.

7. Barrett, J. C., Lamb, P. W., Wang, T. C., \& Lee, C. T. (1989). Biological Trace Element Research, 421-429.

8. Bhaskar Das, M. M. (2009). Water Quality, Exposure and Health, 5-21.

9. Borgono, J. M., Vicent, P., Venturino, H., \& Infante, A. (1977). Environ Health Perspect, 13-24.

10. Branislav Petrusevski, S. S. (March 2007). IRC International Water and Sanitation Centre, 61.

11. Byron, W. R., Bierbower, G. W., Brouwer, J. B., \& Hansen, W. H. (1967). Pub.Med.gov.

7 Danan, M., Dally, S., \& Conso, F. (1984). Pubmed.

8 Ding, G. (1987). J.China Med Univ, 368-371.

9 Dipankar Chakraborti 1, M. K. (2004). J Environ Monit, 74-83.

10 Dipankar Chakraborti, S. C. (2003). Environ Health Perspect, 1194-1201.

11 Eeva-Liisa Sainio, Riitta Jolanki, Erkki Hakala, \& Lasse Kanerva. (2001). Research Gate, 5-10.

12 Feldman, R. G., Niles, C. A., Kelly-Hayes, M., Sax, D. S., Dixon, W. J., Thompson, D. J., \& Landau, E. (1979). pubmed.

13 Fishbein, L. (2006). international journal of environmental analytical chemistry, 21-69.

14 Fowler, B. A. (1983). Biological and Environmental Effects of Arsenic, Volume 6.

15 Giberson, A., Vaziri, D., \& Mirahamadi, K. (1976). Arch Intern Med, 1303-1304.

16 Guangqian Yu, D. S. (2007). Environ Health Perspect, 636-642.

17 Harvey, J., Erdos, G., Bolam, H., \& Cox, M. (2002). Work and Stress, 18-36.

18 Hoffman, G. R. (1991). international journal of ecosystem.

19 IARC. (1980). Lyons International Agency for Research on cancer, 39-41.

20 J. M. McArthur, 1. P. (2001). Water Resources Research, 109-117. 
21 KC, S. (1984). Melanokeratosis from arsenic contaminated tubewell water. Ind. J. Dermatology, 37-46.

22 Khalid, N., Hameed, M., Ahmed, R., \& Hussain, M. (2017). research gate.

23 Kurisu, F., Ramanathan, A. L., Kazmi, A. A., \& Kumar, M. (Eds.). (2017). Springer International Publishing.

24 L., F. (1987). Int. J. Environ.Annl.Chem, 21-69.

25 Lars Gerhardsson, E. D. (1988). Scandinavian Journal of Work, Environment \& Health, 130-133.

26 Leonard, A., \& Lauwerys, R. R. (1980). Mutat Res., 49-62.

27 Morton, W. E., \& Caron, G. A. (1989). PubMed.

28 Muhammad Bilal Shakoor, Bibi, I., Shahid, M., \& Niazi, N. K. (2018). Chemosphere, 737-746.

29 Muhammad bilal shakoor, nabeel khan niazi, Irshad Bibi, Muhammad Shahid, Zulfiqaar ahmed saqib, Muhammad Farakh Nawaz, Jörg Rinklebegm. (2019). Environment International, 567-579.

30 Mukherjee, A., Bhattacharaya, P., Jacks, G., \& Banerjee, D. M. (2006). Research Gate.

31 Munish K. Upadhyay, P. Y. (07 May 2018). frontier in environmental science.

32 Palit, S., Misra, K., \& Mishra, J. (2019). Separation Science and technology, 113-123.

33 Paramita Mandal. (2017). Eemerging Contaminants, 17-22.

34 Peplow, D., \& Edmonds, R. (2004). Environmental geochemistry and Health, 69-79.

35 Petrusevski, B., Sharma,, S., Schippers (UNESCO-IHE), , J. C., \& Shordt (IRC), K. (2006). Arsenic in. IRC, 60-62.

36 Saha, J. C., Dikshit, A. K., Bandyopadhyay, M., \& Saha, K. C. (1999). Critical reviews in environmental science and technology, 29(3), 281-313.

37 Saha, K. C., Saha, J. C., Bandyopadhyay, M. A., \& Dikshit, A. K. (1999). critical reviews in environmental science and technology, 281-313.

38 Saldana, R., Juarez M.R , A., A.L., S. R., N., S. R., C., O., \&-GUTIÉRREZ-CHÁVEZ, A. J. (2018). Irapuato, Gto., México, 19.

39 Samrana S1, 3. A. (2017). Ann Agric Crop Sci, 1027.

40 Sandhu, S. S., Ma, T. H., peng, y., \& Zhou, X. (1989). Mutation Research/ Genetic Toxicology, 437-445.

41 schoolmeester, W. L., \& White, D. R. (1980). south med J., 198-208.

42 Shrestha, R. (2012). Inquiries Journal, 3.

43 Squibb, K. S. (1983). Elsevier, New York, 233-269.

44 Stewart T. Reed, T. A.-S. (2015). Agricultural Sciences, 495-466.

45 Sun GX, W. P. (2008), (Environ sci technol). 7542-7546.

46 Thirlwall, J. M. (2001). Water Resources Research, 109-117.

47 Tseng, W. -P. (1977). NCBI, 109-119.

48 Yih, L. H., Huang, h., Jan, K. Y., \& LEE, T. C. (1991). Cell Biology International Reports , 253-264.

49 YJ, Z., \& JM., D. (2008). environ sci technol, 56-60.

50 Zaldivar, R. (1974). Beitr Pathol, 384-400. 